\title{
艺术类现代学徒制培养模式的探索与研究 -一以摄影摄像技术专业为例
}

\author{
曹博 \\ 泉州华光职业学院 \\ DOI:10.32629/mef.v3i4.797
}

\begin{abstract}
[摘 要] 本文针对职业院校与企业在现代学徒制人才培养模式中出现的协同育人、教学管理等问题进 行探索与研究。通过校企建立深入往来, 充分分析学校实训室和企业工作环境差异, 通过现代学徒制 试点项目中出现的各种问题, 寻找实际有效的解决方案, 打通人才培养通道, 做到科学管理; 分析企 业实际用人需求, 做到校企零距离, 互通教学课程, 让学生学得专、用得上, 提高人才培养动力; 借 鉴相关专业群中较成熟的订单形式孵化培养模式和教学管理方法, 满足企业人才需求。
\end{abstract}

[关键词] 现代学徒制; 问题研究; 人才培养; 产教融合

\section{Exploration and Research on the Training Mode of Modern Apprenticeship in Art \\ - Take the Professional Photography Technology as an Example}

Bo Cao

Quanzhou Huaguang Institute

\begin{abstract}
[Abstract] This article explores and studies the problems of collaborative education and teaching management in the modern apprenticeship training mode of vocational colleges and enterprises. Through the establishment of in-depth contacts between schools and enterprises, it fully analyzes the differences between the school training room and the working environment of the enterprise. Through the various problems in the modern apprenticeship pilot project, it finds practical and effective solutions. Besides, we should open up talent training channels to achieve scientific management; analysis the actual employment needs of enterprises to achieve zero distance between schools and enterprises, and exchange teaching courses, to make it professional and useful for student, and improve the motivation of talent training; learn from the more mature order form incubation training models and teaching management methods in related professional groups to meet Enterprise talent demand.
\end{abstract}

[Key words] modern apprenticeship; problem research; talent development; industry-education integration

现代学徒制是建立在学校、企业、 学生三方共同认可, 由校企深度合作, 校内教师与企业师傅联合培养，充分提 升学生职业技能的现代人才培养模式。 根据《教育部关于开展现代学徒制试点 工作的意见》精神。现代学徒制有利于 促进行业、企业参与职业教育人才培养 全过程, 实现专业设置与产业需求对接, 课程内容与职业标准对接, 教学过程与 生产过程对接, 毕业证书与职业资格证 书对接, 职业教育与终身学习对接, 提
高人才培养质量和针对性。通过对艺术 类相关专业的教学改革, 对摄影摄像技 术等艺术类专业现代学徒制试点的人才 培养模式进行研究。并在实施过程中积 极探索与实践, 通过对毕业生调查、相 关行业和高校对于开展现代学徒制的横 向调查, 在加强校企合作过程中, 解决 院校与企业在人才合作培养中的实际问 题, 推进和规范学院人才培养工作, 进 一步推进艺术类相关专业应用性人才的 特色与创新培养。

\section{1 人才培养过程中的诸多问题}

作者所在学校参与现代学徒制的专 业有摄影摄像技术、数字媒体应用技术、 服装与服饰设计、影视动画等专业。针 对学校与企业共同培养过程中出现的问 题, 如: 不同年级学情与实习岗位不相 适应问题、企业对现代学徒制项目的接 受与内涵理解问题、管理责任归属问题、 企业导师专业技术转化知识点的沟通问 题、学生到员工的身份转换问题、校内 教师教学知识点转化实训项目问题、实 
习工作时长、工作量与在校学习不均衡 问题、学生对企业文化的认知与企业师 傅认可学徒身份的问题、学生实习过程 中生活条件与后勤管理问题、实习待遇 与工作效益的衡量等诸多细节问题展开 研究。通过梳理, 归纳为以下几方面:

1.1 企业认知不足。根据《福建省教 育厅办公室关于做好2018年度国家现代 学徒制试点工作的通知》 (闽教办职成 〔2018〕13号）的相关要求，本校相关 专业与企业联合申报现代学徒制项目, 由校企共同设计人才培养方案及教学标 准与管理实施方案。企业由于距离远、 业务忙、缺少专项负责、对现代学徒制 项目的内涵理解不足等种种原因, 没有 将项目作为企业工作重点来应对。在项 目落地后, 仅仅是把项目当做普通的校 企合作学生实习安排。使得校企双方难 以实现人才培养的深度融合。

1.2 岗位技能与教学实施衔接。在技 能转化方面出现如下两点问题: 其一, 企业导师在专业技术转化成知识点上出 现沟通问题。企业导师的技术非常成熟 实用, 但因为缺乏引导学生的经验, 很 难通过循循善诱、因材施教等教学技法 来与学生进行沟通, 从而进一步强化学 生在校所学的知识点, 做不到学以致用, 出现学用脱节的现象; 其二, 校内教师 出现教学知识点转化实训项目过渡困难 的问题。校内教师具有很强的理论功底, 也有许多实训教学案例, 但知识点过于 专业化, 在这些实操性较强的专业上显 得较为突兀，甚至有些思维固定化，学 生在校期间闭门造车的思维限制了进入 企业后的动手实操能力。

1.3 学生管理欠缺。在学生管理方 面, 首先出现的就是管理责任归属问题。 现代学徒制中, 学生虽然是企业未来的 员工，但身份依然是学校的学生。企业 认为, 学生应该归学校管理, 而学校认 为, 学生进入企业实习, 学生作为准员 工，管理自然是归属企业。所以管理责 任归属难以定论, 学生出现 “散养” 状 态, 存在隐患。其次就是学生实习过程中 生活条件与后勤管理问题。多数学生反映 在实习过程中生活条件不如人意, 企业的
认知是一个原因, 没有从思想上认为学生 是本企业的员工, 用普通校企合作的思维 定式认为学生单纯仅是实习, 没有考虑的 到长远的培养计划, 因此在生活条件和后 勤管理方面不甚上心, 让学生的心理出现 较大落差感, 不利于企业用工情绪。再次 就是实习待遇与工作效益的衡量的问题。 因为企业的普遍认知中, 学生的实习身份 是短期的, 无长足规划, 所以实习待遇就 无法与工作效益对等, 学生在企业工作环 境中, 对比同工却不同酬的状况, 自然难 以接受。

1.4 学生心理认知问题。学生认知主 要体现在如下三方面: 第一, 大部分学 生存在从学生到员工的身份转换的接受 过程较长问题。学生于大二进入企业实 习两个月, 自身对学校还有一定的依赖 心理, 而进入企业后, 大部分学生是直 接上 “一线” 了, 他们从思想上还很难 快速适应企业的用工快节奏。另外, 在 学校时, 无论是作业还是相关的专业考 试, 都有一个时间和心理的缓冲期, 并 且有一个评估标准。而进入企业后, 每 一次的工作作品和结果都直接呈现, 没 有过程性的评价, 学生会茫然, 不知自 己在企业中所上交的 “作业” 能否合格, 因此在身份转化上就有一个接受过程。 第二, 实习工作时长、工作量与在校学 习不均衡问题。学生在实习过程中单位 工作时长、工作量都是配合企业的节奏, 无法像在校期间有严格的学习时间。这 让学生的学习时间不规律, 接受知识和 技能的能力就无法保障。因为人的注意 力集中时间是有规律可循的, 长久地让 大脑皮层处于兴奋和紧张状态就难以维 持注意力, 工作时长与知识接受度就自 然呈反比了。这样的工作强度不利于学 生的身心健康, 同时也不利于企业的工 作效益。第三, 学生对企业文化的认知 存在认知不全或认知有误的问题。每个 学生的知识架构和理解能力决定了其能 否对企业的文化认知与企业自身所标榜 的形象相吻合。部分学生按照自己的理 解来诠释企业文化, 会出现一定误区, 在一定程度上也影响了其在就业表现中 的优胜劣汰。
1.5 企业师傅接受度。企业师傅认可 学徒身份的问题。现代学徒制是企业师傅 带徒弟的模式, 但又有别于传统的学徒模 式。需要用现代化的互联网+等思维, 在 企业中手把手教会徒弟技能，让徒弟（即 学生）做到学以致用、举一反三，使其基 本功配合技术更加扎实, 在实践中出真 知。而当代企业大部分都是批量化生产模 式, 为了迎合市场的快速发展和需求, 企 业需要快餐化培养人才, 这与学校培养扎 实功底学生的培养目标不能高度统一, 存 在一定冲突, 所以要协调好企业师傅的认 知, 从思想上植入现代学徒制的培养模 式, 还有一段很长的路要走。

\section{2 设立调查及分析}

结合艺术类相关专业的人才培养特 点, 通过现代学徒制校企零距离, 互通 教学课程, 满足企业人才需求。通过对 学院相关专业的教学改革研究, 一方面 对摄影摄像技术专业群相关专业毕业生 进行专项调查问卷, 另一方面对艺术类 相关专业的行业企业单位进行问卷调 查, 最后对高职院校的实习管理情况进 行专项调查。

2.1 毕业生实习与就业情况调查。毕 业生专项调查对象为摄影摄像技术等相 关专业的已结束校外顶岗实习的三年级 学生。在专项调查中, 提出了专业的研 究与运用、创业与就业意向、实习工资 待遇等问题, 以及本专业教学和学生关 于实习、就业方面的需求进行了调查, 调查初步对专业人才培养与社会需求的 研究提供了依据。调查反映了受调查者 在专业研究、创业与就业方面的总体认 知与需求, 以及实习、工作过程中所产 生的诸多细节问题, 同时, 通过交叉分 析, 发现了不同专业方向的学生对专业 知识的理解与应用的差异。通过调查了 解到, 学生在创意与技术应用方面中能 够注意到专业技能方面学习加强的必要 性和重要性。在专业技术的提升方面, 学生普遍认为参加实习单位实践更能提 高自身专业素质。学生对本专业的培养 重点需求在专业技术和市场调研方面, 说明学生能够认知到专业技能应用与研 究相对较重要。学生在校期间进行创业 
培养的必要性和重要性。“外出实践” 是 大部分的学生在学习期间所期望的。在 企业进行技术支持的过程中学生更希望 获得技能操作方面的信息。经调查, 目 前实习期间的学生主要服务于淘宝网拍 拍摄、婚纱写真影楼、摄影工作室、机 构培训和美容院, 说明电子商务、教师 行业和服务行业已经成为了学生选择的 热门就业渠道。调查中学生在行业中主 要担任摄影助理和摄影师、培训老师、 美容师的工作, 基本上学生还是能从事 和本专业较符合的工作。在待遇方面学 生的期望值较高, 与实际的收入有一些 差距, 说明学生更希望服务高端市场。 目前学生的普遍工作报酬在 3000 元左 右, 大部分收入集中在2000-4000之间。 实际人才培养中, 所有专业的学生均在 专业技法和市场调研与营销方面感觉差 异较大, 说明实际人才培养需要在专业 技法和市场调研与营销方面加强。在校 课程也要做适当的调整。在实习期间的 学生能在实际工作当中感受到经验积累 与技能培养的重要性。

2.2 企业人才需求调查。为更好地了 解摄影摄像技术等相关专业人才培养的 需求, 作者通过调研采集, 对全国 110 家企业单位进行问卷调查。其中民营企 业63.64\%，独资企业22.73\%，合资企业 $9.09 \%$, 国有企业 $4.55 \%$ 。在对企业与院 校建立校企合作形式的需求调查中, $41.82 \%$ 的受访企业希望以生产性实训 基地形式合作，39.09\%的受访企业希望 以社会培训服务的形式合作， $17.27 \%$ 的 受访企业希望以校中企的形式合作， $14.55 \%$ 的受访企业希望以订单班或冠 名班的形式合作。由此可见, 企业希望 与学校共建实训基地来提升学生的实际 操作能力, 也希望通过培训服务介入学 校的人才培养。但目前在校企深度合作、 产教融合方面, 大部分普通本科院校根 据其办学性质还无法像高职院校有多种 灵活合作形式。这也是高职院校紧贴行 业的优势。在对人才专业素养需求及企 业处理人才关系的调查中，专业对口率 占 $68.18 \%$, 学生管理责任归属问题占 $21.82 \%$, 校内教师教学知识点转化实训
项目占 $21.82 \%$, 实习待遇与企业工作效 益的关系占 $20.91 \%$, 学生对企业文化的 认知占 $19.09 \%$, 学生到员工的身份转换 教育占 $15.45 \%$, 企业将专业技术转化知 识点占 $15.45 \%$, 实习工作时长与劳动强 度占 $14.55 \%$ 。由此可见, 企业对人才专 业素养需求和人才关系存在差异。

综上所述, 相关行业需要从事摄影 造型、影像文化创意等方面的系统影像 制作和影像管理与研究的高素质强技能 创新性人才, 相关企业更需要掌握相关 技术知识又具备分析、解决实际问题能 力的应用型人才。

2.3 院校实习管理调查。该项调查对 象包含福建、江苏、北京、山西、陕西、 湖北、河南等东部、中部、西部省 (市), 涉及公办本科、民办本科、独立学院、 公办高职、民办高职等30所院校。其中, 高职院校占18所, 职业技术大学 (本科 层次职业教育) 1所。在 “现代学徒制” 培养项目 (以下简称项目) 的专项调查 中, 提出了校企合作形式、专业特性和 实习项目、实习岗位与实习周期、学生 实习需求等问题。

在调查的18所高职院校中, 有16所 院校开设过项目。另外, 一些由专科升 格为本科的院校也参与过该项目。说明 项目涉及院校较多。参与项目的已有毕 业生占 $56.25 \%$, 说明有一半的院校至少 在3年前就开展了此项目。但学生毕业后 仍留在项目合作单位工作的仅占小部 分。参与项目的专业大多数属于学校重 点专业和企业配合度较好专业。参与项 目的专业的实习岗位基本上能够满足企 业数量需求, 与岗位持平, 说明大部分 企业能够合理调配好实习岗位数量。同 专业或相近专业中, 项目与非项目在人 才培养方案上的仅有较小差异。

通过调查得出, 各本科、高职院校 校企合作形式多样, 如: 生产性实训基 地、订单班、冠名班、校中企、企中校、 横向课题、社会培训服务、产业学院等。 本科类校企合作主要以生产性实训基地 和横向课题为主, 而高职院校校企合作 主要以社会培训服务、生产性实训基地、 订单班和校中企为主。绝大多数高职院
校围绕师资较好的重点专业和企业配合 度较好专业开展 “现代学徒制”、“二元 制” 等人才培养项目, 且在开展的项目 中实习岗位数量与学生实习数量基本持 平。大部分企业比较支持相关的人才培 养项目, 绝大多数学生也较认可这一类 人才培养项目。大一、大二的学生在企 业实习的时间大部分为 1-3个月。

在处理学校、企业、学生在校企合 作中的关系中, 大部分本科院校认为校 内教师教学知识点转化实训项目、专业 对口率、企业将专业技术转化知识点等 问题是重点考虑的, 而大多数高职院校 认为企业师傅将专业技术转化知识点、 校内教师教学知识点转化实训项目、学 生到员工的身份转换的教育是应重点考 虑的。部分高职院校还认为应考虑企业 师傅对学生学徒身份认可度。注重引导 企业师傅将专业技术转化知识点和加强 校内教师教学知识点转化实训项目。注 意实习阶段学生日常管理的责任归属问 题, 学生实习待遇与企业工作效益的关 系等等。

\section{3 具体问题解决对策}

3.1 校企深度合作、协同育人。针对 企业对现代学徒制的认知, 除了与具有 校企双主体育人经验的在本行业中有较 大规模企业作为试点单位外, 还应与企 业共同协商现代学徒制中的科学管理、 资源共建和激励政策。从合作初期就重 视该项目。在开展项目申报之前, 通过 行业指导委员会联合有条件、有意愿、 有影响的企业共同探讨现代学徒制试点 项目, 对有意向的企业进行深度交流, 说明政府对该试点项目的扶持力度和对 企业的激励政策。通过试点项目将企业 文化植入校园, 加深学生对企业文化的 认可度, 并强调未来各岗位人才储备的 重要性。统筹利用好校内教学、实训条 件和企业实习环境、工作岗位等教学资 源, 进一步了解行业对一线技能型人才 的需求规格、职业能力要求及专业课程 设置的反馈，进行专业技术职业岗位能 力分析, 会同专业教学指导委员会共同 研讨、制定人才培养模式及其改革方案。 应明确学生参与现代学徒制试点项目在 
企业的实习, 并不是单纯的上岗工作性 质, 更重要的是通过工作过程进行有效 的学习总结, 从而提升学生在行业应用 中的综合素质与实际工作能力。

3.2 优化教学质量评价。校企共同制 订基于工作过程的专业教学标准、课程 与实习标准、师傅标准、质量监控标准 及相应实施方案。校企共同建设基于典 型工作过程的专业课程体系，开发基于 岗位工作内容、融入国家职业标准的专 业教学内容和教材。通过双方的共同发 力, 贴合学生实际情况与实践过程中出 现的问题, 最大限度优化教学质量, 增 加合作效益。

3.2.1积极培育双师型教师。在开展企 业实习前, 组织校内指导教师根据人才培 养方案及相关课程的实训要求, 与企业师 傅一同安排周期学习进度。将知识点转化 有效转化为实习技能项目。校内指导教师 定期下企业进行必要的实习实训, 根据合 作企业的实际工作任务指导教师对学生 课程培养和技能提升做相应调整, 以更好 适应行业发展标准。同时将指导教师的企 业实践和技术服务纳入教师考核并作为 晋升专业技术职务的重要依据。

3.2.2增强企业讲师技能转化教学的 应用能力。学生在企业实习期间, 以企业 讲师为主导, 开设基于工作内容的实训课 程, 增强学生与企业导师及企业之间的黏 性, 借以提升企业导师的教学应用能力, 更好为 “现代化学徒制” 的教学服务, 也 让在企业工作期间的学生, 消除紧张, 对 企业更有归属感，促进后续的合作空间为 企业留下优秀人才打下基础。

\section{3 健全管理制度}

完善学徒培养管理机制, 明确校企 双方的职责与分工, 推进校企紧密合作、 协同育人。细化管理制度和必要的岗前 培训。

3.3.1认真履行三方协议。规范学校 招生录取和企业用工程序, 签订学生与 企业、学校与企业的三方协议, 明确学 徒的 “企业员工” 和 “职业院校学生” 的“双重身份”，明确各方权益及学徒在 岗培养的具体岗位、教学内容、权益保 障等。要根据不同企业的特点和学生的
心理认知, 及时明确三方协议, 为学生 及家长说明三方协议内容, 并落实到位。

3.3.2分级管理制度。建立健全与现 代学徒制项目相适应的教学管理制度。 从学校领导、企业主管、校内指导教师、 企业师傅、辅导员、学生班委进行分级 管理。明确各级工作任务。具体流程如 下: 首先是顶层设计层面, 由学校领导 协调现代学徒制计划安排, 再经由企业 主管协调企业师傅的调配; 其次由校内 指导教师制定实习教学计划、实训指导 书并告知学生与企业师傅; 再次由企业 师傅安排实习任务、工作制度及流程并 告知学生与校内指导老师。在以上的程 序进行的同时, 辅导员安排学生实习期 间日常管理制度与学生班委根据指导教 师要求及日常管理制度, 定期上报每日 考勤、作息情况、学习任务上交情况等, 确保实习过程顺利。

3.3.3开展岗前培训。在学生正式上岗 前, 由企业对学生进行岗前培训、学生入 职礼仪培训, 并引导学生熟悉企业工作环 境及要求、明确助理工作任务安排。在前 期以观摩学习为主, 让学生知道助理该做 哪些事情。同时, 实习学生必须以企业员 工标准要求自己, 遵守企业各项规章制 度, 服从企业领导和师傅的安排, 认真学 习技术, 顺利完成企业学习任务。

3.3.4细化上岗流程。在学生实习过 程中, 企业师傅与校内指导老根据学生 的学习特征, 经仔细煁酌商榷后, 制定 学生能够快速领会并能够有效执行的上 岗工作流程。让学生能够在 “做中学” 从而促进在 “学中思”, 以最快速度掌握 技能, 成为有效用工的同时, 也让知识 技能快速转化为实操应用技能。以婚纱 摄影工作为例:（1）客户到摄影基地如 何安排流程 (2) 先跟客户如何交谈拍摄 需求（3）化妆师化妆流程（4）服装的 搭配与选择流程 (5) 拍摄的路线安排, 风格分类, 服装道具的搭配准备 (6) 到 拍摄目的地后分工准备 (7) 摄影师拍摄 对客人的美姿引导、话术交流 (8) 摄影 师对拍摄器材、灯具的使用流程 (9) 主 题的选景, 分类道具的运用, 构图、前 景、背景（10）摄影师拍摄完后的选片
流程

3.3.5完善后勤管理。校企双方密切 关注学生生活条件, 提升住宿、餐饮质 量。学校用一定的项目补贴资金给企业, 而企业也增加生活条件的投入，用以解 决以往学生普遍反应的住宿条件差, 距 离实习地远的问题。而关于企业所集中 反映的因为学生实习时间仅有 $2-3$ 个 月, 较难寻找成本低且住宿条件较好的 短租宿舍的问题, 依然可以通过校企双 方共同解决。如，与固定的集体宿舍签 订每年的固定时间段的承租，或企业整 理建设出员工宿舍等方式。为确保实习 的顺利进行, 还安排专职辅导员进驻管 理学生, 能管理学生生活起居和实习出 勤情况的同时也能给学生带来一些心理 抚慰效果, 加强学生的心理建设, 有利 用工情绪。总之, 校方与企业双方积极 沟通，与企业共同克服困难。

3.3.6创新考核评价与督查制度。基 于工作岗位及工作流程制订学生考核评 价标准, 建立多方参与的考核评价机制。 学生方面, 在月末根据学生的实习总结, 对学生进行学习量化考核。企业方面, 建立定期检查、反馈等形式的教学质量 监控机制。学校方面, 定期与企业及时 沟通，互相督促，建立双监制。

3.4提升学生认知。

3.4.1设定学习清单。根据上岗流程 制定统一的学习内容清单, 由学生逐项 完成清单内容, 并针对清单项目进行总 结与反馈。以婚纱摄影师工作清单为例, 见图表:

学生根据工作清单按周完成实训报 告并提交给企业师傅, 企业师傅根据学 生的实训报告, 进行指导性建议, 并协 同校内指导老师进行集中反馈。

3.4.2记录学习成长轨迹。引导学生 设定学习计划, 根据实习过程制定学习 进阶表, 主动记录自己的学习成长轨迹。 在课题研究期间, 作者通过征集, 获得 一位学生的记录, 他是这样写自己的实 习成长历程的:

第一周，如何协助摄影师，找服装， 整理主题道具、灯光; 第二周, 及时了解 摄影师的拍摄意图, 进行补光 (补光技巧 


\begin{tabular}{|c|c|}
\hline 时间 & 学习内容 \\
\hline 第一周 & 参观企业, 了解企业及企业文化 \\
\hline 第一、三周 & 熟悉婚纱摄影的拍摄流程 \\
\hline 第一、三周 & 服装的搭配与选择 \\
\hline 第一、二周 & 拍摄的时间流程, 场地的分配 \\
\hline 第一、三周 & 拍摄的路线风格与分类, 服装道具的搭配 \\
\hline 第二-四周 & 摄影师拍摄的引导与交流 \\
\hline 第三、三周 & 摄影助理反光的使用 \\
\hline 第三一五周 & 头纱、花、眼神等细节的把握 \\
\hline 第三一五周 & 摄影师的拍摄美姿分类 \\
\hline 第四-六周 & 男生背景、景别的分类 \\
\hline 第五-六周 & $\mathrm{XX}$ 主题的分类道具的运用, 美姿、构图、前景、背景选择 \\
\hline 第六-七周 & 自然光下摄影师如何寻找光影, 拍摄高度变化, 场景选择 \\
\hline 第六-八周 & 草地、街景、海景的拍摄主题方案 \\
\hline$\cdots \cdots$ & \\
\hline
\end{tabular}

的掌握) 第三周, 引导客人 (注意自己的 交流话术)，整理摄影师跟客户的交流语 言，熟悉师傅的拍摄流程；第四周，学习 师傅的构图特点, 拍摄䛎门; 第五周, 充 分利用休息时间跟师傅进行沟通, 交流拍 摄经验; 第六周, 双机位练拍学习, 锻炼 镜头感, 缩短与客户之间陌生感; 第七周, 主题婚纱的深刻认识与理解, 主题婚纱意 境、婚纱背景道具的搭配; 第八周, 外景 的背景选择与光线处理, 拍摄时的镜头 感, 构图特点, 道具的灵活运用。由以上 的记录中不难看出, 学生每周都在成长, 获取新的技能, 制定了较为完善的学习计 划, 这就是让学生到 “一线” 学习的优势, 也是 “现代学徒制” 的培养模式的意义所 在。另外, 企业可以每周根据企业工作周 期, 为学生安排独立的创作、练习时间和 必要的设施设备, 让学生对所学知识进行 消化和实验。

3.4.3设立激励政策。为学生提供交 流学习场所, 对学生提交的习作进行积 极点评, 定期进行学习交流。通过一些 激励政策, 提高学生实习热情。对于表 现积极、态度认真、工作负责, 并且无 迟到、早退的学生给予额外奖励, 定期 评选优秀学员。

3.4.4及时发现实习过程中的矛盾。 学生在进入实习期之前就开展跟岗教 育。培养学生良好的职业道德, 要求学 生在企业学习期间必须尊重企业师傅, 对于出现的突发事件和问题及时向校内 指导教师或企业经理反映。制订学徒管
理办法, 保障学生权益, 根据教学需要 科学安排学生岗位、制定工作计划、分 配工作任务, 保证学生合理报酬。同时, 企业要合理安排学生工作量。工作时间 应等于或少于正常员工上班时间。发现 学生在实习过程中的各种问题, 积极进 行心理疏导。对学生由于特殊原因需要 离开企业的情况, 应及时报备给企业经 理和带队指导教师, 并稳定其他实习学 生情绪。同时, 还应严格落实参与现代 学徒制项目学生及教师的各类保险, 确 保师生人身安全。

3.5 完善双导师制。建立灵活的人才 流动机制, 为保证教学质量, 校企双方 共同制订双向挂职锻炼、联合技术研发、 专业建设的激励制度和考核奖惩政策。 通过组建校内技能大师工作室、校企共 建课程与教材开发等项目，提升

3.5.1 技能大师工作室。完善双导师 制, 建立健全双导师的选拔、培养、考核、 激励制度, 形成校企互聘共用的管理机 制。明确导师的职责和待遇, 合作企业选 拔优秀高技能人才, 由学校为其建设技能 大师工作室。并对企业摄影师进行工作量 现金补贴, 增加企业师傅的积极主动性。 通过组建校内技能大师工作室, 为企业讲 师和学生设立交流空间, 企业师傅能够带 给学生从浅到深过程的阶段性学习机会。 同时, 学生通过提前交流, 增加亲和力, 减少实习期不必要的师徒沟通障碍。

3.5.2课程与教材开发。根据专业人才 培养方案, 与企业制订与实训相配套的教
学课程, 将基于工作过程的知识点融入教 学。同时参与相关专业的教材编写工作。 另外, 积极与企业联合申报横向课题。

3.5.3 职业能力拓展。对接国家 $1+\mathrm{X}$ 证书制度试点工作, 重点培养与专业相 关的职业能力。通过以上形式的校企合 作, 围绕市场急需的专业人才职业能力 进行理论与实践的教授。让学生在校期 间就能够与企业零距离接触, 并达到企 业的用人要求。并借助校企共建企业项 目实训室、校中企、技能大师工作室等 项目，提高技术技能人才的培养水平。 注重实际能力的培养, 邀请企业讲师通 过抖音、腾讯课堂等直播工具定期开展 线上直播课, 分享紧贴行业发展的经验。 并进行在线指导、答疑, 增强学生的认 知, 与学生拉近距离。让学生在上岗前 就成为企业师傅的忠实粉丝。

现代学徒制是一个顺应新时代的社 会时势、符合企业和个人职业规划发展 的新型培养模式, 是挑战也是机遇, 及 时抓住优势就能顺势而发, 借力发力, 于学校、于企业、于学生都是大力度的 多赢合作。

\section{基金项目:}

2019年度全国职业教育科研规划课 题: 艺术类现代学徒制培养模式的探索 与研究 (项目编号: 2019QZJ013)。

\section{[参考文献]}

[1]教职成〔2014]9号.教育部关于 开展现代学徒制试点工作的意见[S].

[2]陈姿㷋.高职院校艺术设计专业 现代学徒制人才培养模式探究 [J].决策 探索(下),2020(04):63.

[3]何北宁.对现代学徒制试点工作的 探索与思考[J].宁夏教育,2016(11):6-8.

[4]赵鹏飞. “现代学徒制” 的实践与思 考[J].中国职业技术教育,2013(12):38-44.

[5]高欢.对现代学徒制试点工作的 几点思考[J].现代职业教育,2018(07):51.

\section{作者简介：}

曹博（1982-- ), 男, 汉族, 河南 洛阳人, 副教授, 本科, 主要从事广播 影视类教学研究。 